\title{
XLIII. Observations on the changes produced in the new wheat; and on the means of improving the flour
}

\section{Edmund Davy Esq.}

To cite this article: Edmund Davy Esq. (1817) XLIII. Observations on the changes produced in the new wheat; and on the means of improving the flour, Philosophical Magazine Series 1, 49:227, 173-178, DOI: 10.1080/14786441708637874

To link to this article: http://dx.doi.org/10.1080/14786441708637874

电 Published online: 27 Jul 2009.

Submit your article to this journal $\pi$

Џll Article views: 2

Q View related articles $₫$ 
trough have a slider to cover the grating, which can occasionally be drawn up. Put two or three bushels of lime at a time into the trough; throw plenty of water on it, and mix it well up with a large hoe perforated with holes. When there is a good quantity of liquid, draw up the slider, and let it run into the pit. The trough should have a small inclination, and hang six or eight inches over the pit. Throw more water on the remaining limestones, and those which will not slack are not sufficiently burnt, and may be returned to the kiln.

After lime, thus slacked, has been a few hours in the pit, it will take the consistence of paste, which it will preserve for years. It should be kept covered, to keep it clean and exclude the fixed air floating in the atmosphere, as well as to preserve it from heat or cold, especially the latter, as frost destroys it. For those who use larger quantities several pits should be dug, in prefercnce to larger ones;-for smaller quantities a lesser pit may be used.

This lime mixed with water is very superior to whiting for whitewash, and, as it requires no size, is much more wholesome, as the nauseous effluvia from size, which always attracts damp, cause an insupportable smell. It gives a resplendent white for ceilings, and has a peculiar tenacity on walls, and in situations exposed to wet. It has the advantage of always being ready for use; for when mixed with a little water and a proper proportion of sand, mortar is prepared in a few minutes. According to my own experience, this lime is equally good after lying several years in the pit: and any one acquainted with this nethod of treating lime, and the process usual in England in preparing mortar, will not hesitate in giving this the decided preference.

XLIII. Observations on the Changes produced in the new Wheat; and on the Means of improving the Flour. By EDmusp Davy, Esq. Professor of Chemistry and Secrelary to the Cork Institution.

\section{To Mr. Tilloch.}

Dear Sir, $-T_{\text {HE subject on which I recently addressed you* }}$ lias since occupied my attention. I have extended my researches, and selected from previous inquiries such observations and experiments as were unnoticed in my late communication.

It appears to be an indisputable fact, that the average quality of the last year's wheat is very inferior to that of former years. Whatever defects it may possess, they must be referred to changes produced in the grain in consequence of the unfavourable cir* See p. 161. 


\section{Olservations on the Changes produced in the new Wheat}

cumstances under which the crops ripened or were saved in the late unpropitious harvest. Every attempt, therefore, to improve the new flour for the purpose of making bread, ought to be founded on some previous knowledge of the injury the wheat had sustained. The hope of being able to correct the bad qualities of the four, induced me more than two months ago to turn my leisure moments to the subject. I entered on the investigation with some preliminary experiments on the new wheat and flour. I examined several samples of new wheat: they had all to a certain extent undergone the process of germination or incipient vegetation. In some cases the germen had protruded from about $1-10$ th to $5-10$ ths of an inch, and the radicle from about 1-10th to above an inch in length. These were, it is true, the very worst samples I could procure. I likewise examined several specimens of wheat from different parts of this county, of a quality far superior to those I have mentioned; but in all of them it was discoverable on a minute inspection that a slight and partial germination had taken place. And I have been given to understand, that the average wheat of the country has suffered more or less in this way. Some crops germinated before they were ready for the sickle, and others after they were cut down and made up into sheaves.

As the natural germination of the wheat appeared to be similar to that effected by artificial means, in the malting of barley, in which a portion of the farinaceous part of the grain is converted into saccharine matter, I made some experiments with a view to ascertain how far this opinion was well founded. I placed different samples of new wheat in tin dishes, and thoroughly dried them on a hot iron plate. The grain had a sweerish taste resembling malt, and afforded with warm water an infusion which when boiled down nearly to dryness had a sweet taste, and consisted of saccharine and mucilaginous matter.

I mixed some new seconds flour of bad quality with distilled water. After about forty hours the fluid was passed throngh a filter. The solution had a slight sweetish taste; on being boiled a little albumen coagulated, and after the fuid was evaporated to 1-14th of its original volume, the residual liquor was quite sweet to the taste, and consisted of mucilage and sugar. $\mathrm{O}_{1}$ making a comparative trial with good old flour, the yuantity of saccharine matter obtained was, in proportion, very inconsiderable.

I made bread with the new seconds four, warm water, axl yeast, without any salt. Some of the bread was put in distilled water for twenty-four hours; the clear fuid was then decanted and boiled down nearly to dryness. The residual liquor wns sweet. It was further evaporated and digested in warm alcohol. 
The sugar was dissolved by the spirit, and there remained a white substance which dissolved in cold water, and was principally mucilage. The spirituous solution was boiled to dryness, and the sugar remained. It tasted of the spirit, and was also nixed with a little mucilage.

From these trials it seemed probable that the bad qualities of the new flour were connected with the production of saccharine matter in the grain; and this opiniun acquired additional evidence from the following experiments.

I made two small loaves; each contained haif a pound of the best old flour and the same quantity of yeast and salt. In fact, they were in every respect similar, with the exception that one contained 100 grains of soft sugar. Before they were baked, it was observed that the dongh with the sugar was not quite so light, it had not apparently fermented so well as the other. The loaves after being taken from the oven and suffered to conl were examined. The loaf without sugar appeared to have all the requisites of excellent bread. The property of elasticity it possessed in a high degree. When the soft part of the bread was pressed ever so much by the finger, it immediately regained its former situation without leaving any impression behind. The loaf with sugar had a bitter taste, and especially the crust of it. It was rather disposed to be clammy. It was not nearly so elastie as the bread without sugar. When pressed on by the finger it slowly recovered its situation, but the impression was left behind. The colour of the bread with the sugar was also a little impaired. I made a similar trial with good old American flour, and the resulta corresponded very nearly with those detailed; the hread with sugar had a bitter taste, and slightly adhered to the teeth; whilst the bread without sugar was excellent, and did not possess those properties in any degree. As an infusion (of the bread containing sugar) in cold water had a sweetish taste and did not affect litmus paper, it is likely a part at least of the sugar remained unaltered in the bread.

From these experiments it would appear, that the quality of bread made from good flour, with the usual additions, is impaired by sugar; as the dough with sugar did not rise quite so well, nor was the bread so light as without sugar. I should conceive this substance tended rather to check than to accelerate fermentation in such circumstances. A certain portion of succharine matter seems essential to the panary fermentation. Good wheat appears to possess the requisite quantity, which, if it be increased by artificial or natural means-whether it be simply added to the flour, or produced by the germination of the grain,still it seems to act by retarding the fermentation requisite to produce good bread, or bread in its greatest perfection. The case 


\section{Olservations on the Changes produced in the new Wheat;}

is somewhat similar with preserved fruits beginning to undergo the acetous fermentation; when they are heated with more sugar, this process is checked, and all further chemical changes are suspended. Common salt and other saline substances, as is well known, are powerful antiseptics when used in quantity, but when employed in small proportion they promote putrefaction. Sugar in a similar way appears to retard or promote fermentation.

The efficacy of the method recommended by Mr. Hatchett of improving damaged and musty corn, by exposing it to the agency of hot water, may in part depend upon its dissolving out a portion of the saccharine as well as the musty matter of the grain.

The means recommended to improve the new flour for making bread, are 1. By drying the flour. 2. By mixing with the flour or the dough some innocent and cheap material. The flour may be dried either slouly, by exposing a large surface of it before the fire for several hours, and occasionally turning it over; or rapidly in an oven, or by the agency of steam. With a view to ascertain the most efficient mode of drying the flour. I made the following experiments on new seconds of bad quality.

Exp. 1.-One pound of flour in a shallow tin dish was placed before the fire, and occasionally turned over. After twenty-four hours it lost one ounce in weight. The bread from it was of a better colour, lighter, and rather better-tasted than the flour would have furnished before it was dried. Still, however, it had a disagreeable taste, which was effectually corrected by the carbonate of magnesia, when used in the proportion of thirty grains to a pound of the flour.

Exp.2.-One pound of flour in a tin dish was placed on an iron plate for eight hours, at a temperature varving from about $200^{\circ}$ to $230^{\prime}$. It lost two ounces in weight. The bread from it was not improved, but heavy, clammy, and of a bad colour.

Exp. 3.-One pound of flour in a dish was put into the over and exposed to a temperature varying from about $212^{\circ}$ to $250^{\circ}$ for three hours; it lost nearly an ounce in weight. The bread from it was very little better than that of the preceding experiment.

To ascertain whether the flour, by being slowly dried, lost any thing besides moisture, I put two ounces of it into a tubulated retort, placed the neck of the retort in a little distilled water, and exposed the retort to the temperature of about $90^{\circ}$ for some time. A little fluid came over. It was colourless and insipid, and did not affect litmus or turmeric paper; and left no residuun on being evaporated to dryness. Hence it appeared to be only water.-These experiments seem to favour the opinion that the advantages resulting from drying the flour are best secured by carrying on this process in a slow and gradual manner. And as 
the new flour in the act of drying appears to lose nothing but water, and after being well dried it still makes bread of indifferent quality, the process of drying can only be regarded as a useful auxiliary, and by no means supersedes the application of other substances as correctives. I have said a moderate warmth, long continued, seems to improve the flour more than a higher temperature. This difference may probably arise from various considerations. As sugar appears to be injurious to flour, and the new flour contains an excess of saccharine matter, and is in a comparatively moist state; a low temperature is most favourable to incipient fermentation, by which process the excess of sweet matter in the flour may be changed into vinous spirit and be dissipated in drying. My experiments have been too limited to enable me to speak accurately concerning the relations of the flour dried in different ways, to water. I obtained one result that was rather unexpected:-I shall state the experiment, but as I had not an opportunity of repeating it I shall decline all comment on it. I dried eleven ounces of bad new flour on a hot hearth; in six hours it had lost nearly two ounces. I nade the dry flour up into dough, but found that it required less water for this purpose than an equal weight of the undried flour.

The principal substances employed to improve the new flour for bread appear to be the alkalies and their compounds, and the subearbonate of magnesia; and I pressume they have been found more efficacious in this way, than any bodies that have yet been tried.

In my former communications I have recommended the use of the subcarbonate of magnesia, and endeavoured to point out its agency when employed in bread. I shall now briefly state some comparative experiments I made, which led me to recommend magnesia in preference to any of the other alkaline substances. I made fourteen small loaves of the new seconds flour of bad quality : each loaf contained half a pound of flour and nearly the same quantity of yeast, salt, and warm water.

No. 1. Loaf containing only the above substances; quite heavy and so clammy as readily to adhere to a knife and the fingers; - bad tasted.

2. Loaf with ten grains of subcarbonate of ammonia in solution;-Lighter and better tasted than No. 1. but rather clammy.

3. Loaf with twenty grains stick potash (kali purum);-Better than No. 1., but not so good as No. 2.

4. Loaf with twenty grains subcarbonate potash;-Pretty good, rather better than No. 2 .

5. Loaf with ten grains American potash;-Improved, but not equal to No. 2.

Vol. 49. No. 227. March 1817. 
No.6. Loaf with eight grains pure potash;-Not so good as No.5.

7. Loaf with eight grains pure soda;-Inferior to No. 6.

8. Lnaf with twenty grains carbonate soda; - Just as bad as No. 1 ; quite viscous, adhering to the teeth.

9. Loaf with forty graius ditto;-Better than No. 8, but inferior to No. 2 .

10. Loaf with ten grains pearlash;-Improved, but not materially.

11. Loaf twenty grains ditto ;-Tolerably good, scarcely inferior to No. 2.

12. Loaf with little pure anmonia;-Scarcely improved, clammy, and bad tasted.

13. Loaf with twenty grains of subcarbonate of magnesia;Very much improved; better than any of the preceding, light and porous, good tasted, and not in the least clammy.

14. Loaf fifteen grains ditto;-Scarcely inferior to No. 13 .

When the new flour is well dried, and the subcarbonate magnesia mixed with it in the quantity of thirty grains to a pound of flour; good bread may be made from such flour with the addition of 1-8th or 1-6th of boiled parsnips, or of baked or boiled potatoes. Baked potatoes seem to answer better than boiled ones; they are drier, and more mealy.

Bread made from the new flour of indifferent or bad quality has a disagreeable smell and taste, is disposed to be heavy and clammy, and has its colour impaired. The disagreeable smell and taste of the bread seem to be connected with the presence of an excess of saccharine marter in the flour, and the subsequent changes it undergoes in the process of baking. The application of the alkaline bodies is explained on the idea that the bread has a tendency to acidity, which is counteracted by their presence; or they neutralize any acid formed, and thus materially improve the bread.

From a comparative trial 1 made, it would appear that the new flour contains a larger proportion of gluten, but less farina, than the old flour. As the gluten of wheat is a very tenacious and adhesive substance, and of a dull gray colour, and farina of a white colour; and as the former is in excess, and the latter in deficiency, in the new flour; - these circumstances may in some measure serve to explain why the bread is disposed to be clammy and of a darker colour than is usually the case.

$I$ remain, dear sir, yours truly,

Cork, Jan. 27, 1817.

Edmund Davy. 